\title{
STUDIES ON A HAEMOLYSIN PRODUCED BY TREPONEMA HYODYSENTERIAE
}

\author{
Ruth M. LEMCKE AND M. R. BurRows
}

\section{A.R.C. Institute for Research on Animal Diseases, Compton, Newbury, Berks RG16 ONN}

SummaRY. Filtrates of Treponema hyodysenteriae grown in rabbit serum broth supplemented with sodium ribonucleate (Na-RNA) $1.0 \%$ contained a haemolysin for sheep, rabbit, and pig erythrocytes. Haemolysin was not detected in the absence of Na-RNA. Haemolytic titres were highest when viable counts were maximal at the end of the logarithmic growth phase. Haemolysin could not be demonstrated in the spirochaete-free supernates of either centrifuged washings from blood-agar cultures, or centrifuged frozen-and-thawed cultures in semi-solid blood agar. In contrast, washed spirochaetes lysed sheep erythrocytes suspended in phosphate-buffered saline (PBS) or PBS-cysteine, provided that bovine serum albumin (BSA) fraction $\mathrm{V}$ was present. Haemolysin was produced aerobically as well as anaerobically. Ultrasonically disrupted spirochaetes did not produce haemolysin.

After incubation for $30 \mathrm{~min}$ at $37^{\circ} \mathrm{C}$, haemolysin was present in supernate or filtrate from centrifuged suspensions of resting cells of $T$. hyodysenteriae in PBS containing glucose or maltose, cysteine hydrochloride, $\mathrm{Mg}^{2+}$, and $\mathrm{Na}-\mathrm{RNA}$ or ribonucleic acid (RNA)-core. By analogy with its function as a non-specific carrier molecule for the oxygen-stable streptococcal haemolysin streptolysin S, ribonucleic acid can be regarded as a carrier substance for the treponemal haemolysin. RNA-core was a more efficient carrier than Na-RNA; BSA fraction V and Tween 80 were less efficient than Na-RNA. Haemolysin was not produced in the absence of a carrier. Haemolysin production occurred at temperatures up to $42^{\circ} \mathrm{C}$, but was reduced at $18^{\circ} \mathrm{C}$ and below. The haemolysin was inactivated slowly at $37^{\circ} \mathrm{C}$ and $42^{\circ} \mathrm{C}$, and more rapidly at $60^{\circ} \mathrm{C}$. Titres also decreased slightly after $18 \mathrm{~h}$ at $4^{\circ} \mathrm{C}$.

Haemolysin was produced in only small amounts by resting cells of a weakly haemolytic porcine-intestinal spirochaete, and only during a restricted period in the logarithmic phase. A prozone was observed when this haemolysin was titrated.

The demonstration that the treponemal haemolysin can be produced from resting cells will facilitate its purification and thus expedite studies on its interaction with other types of mammalian cell. 


\section{INTRODUCTION}

Treponema hyodysenteriae, the spirochaete implicated in swine dysentery (Taylor and Alexander, 1971; Harris et al., 1972b), produces complete $\beta$ haemolysis when grown on blood-agar plates in anaerobic conditions. Picard, Massicotte and Saheb (1979) reported that increased amounts of the haemolysin were produced in fluid cultures of $T$. hyodysenteriae when the medium was supplemented with sodium ribonucleate (Na-RNA). More recently, a 400-fold increase in the haemolytic activity of cell-free filtrates was reported by Knoop (1981) when yeast ribonucleic-acid (RNA)-core was added to the culture medium. The stimulatory effect of RNA suggested that the treponemal haemolysin might resemble the oxygen-stable streptococcal haemolysin, streptolysin S (SLS), in requiring a non-specific carrier molecule for its activity. Purification and characterisation of the treponemal haemolysin derived from culture filtrates was undertaken by Saheb and Lafleur (1980), Saheb, Massicotte and Picard (1980) and Knoop (1981), but haemolysin production by resting cells in the presence of a suitable carrier substance has not been reported. This report describes the conditions necessary for the production of haemolysin by $T$. hyodysenteriae, in particular by resting cells.

\section{MATERIALS AND METHODS}

\section{Micro-organisms}

Treponema hyodysenteriae strains P18A and S73/2 were known to be enteropathogenic for pigs (R. J. Lysons; D. J. Taylor, personal communications). Strain B78-the type strain of the species T. hyodysenteriae (Harris et al., 1972a) - had undergone at least 100 subcultures (D. L. Harris, personal communication). Strains PWS/B, 4/71, PWS/A, and M1 were intestinal spirochaetes isolated from normal pigs, or pigs with conditions other than swine dysentery (Hudson, Alexander and Lysons, 1976; R. J. Lysons, personal communication), and were known to be serologically distinct from $T$. hyodysenteriae (Lemcke and Burrows, 1979, 1981; Burrows and Lemcke, 1981).

\section{Culture media and growth conditions}

Solid medium for spirochaetes consisted of Oxoid No. 2 Blood Agar Base supplemented with sheep blood $5 \%$. Semi-solid blood agar was similar except that the base was diluted with Oxoid Nutrient Broth No. 2 to give a final agar concentration of $0.35 \%$. The semi-solid medium was dispensed in 20-ml amounts in 250-ml Erlenmeyer flasks covered with Oxoid metal caps. The solid and the semi-solid media were incubated, in anaerobic jars, in a mixture of $\mathrm{CO}_{2} 10 \%$ and hydrogen $90 \%$.

Fluid medium was the rabbit-serum broth (RSB) described by Lemcke et al. (1979) except that the concentration of sodium bicarbonate was reduced to $0.2 \%$. In some experiments RSB was supplemented with Na-RNA 0.5 or $1.0 \%$. Inocula were derived from suspensions of known viable count stored in mist. dessicans at $-70^{\circ} \mathrm{C}$ (Lemcke et al., 1979). These were diluted in Trypticase Soya Broth (Baltimore Biological Laboratories, Cockeysville, Md, USA) so that each $50 \mathrm{ml}$ of medium received an inoculum of $1 \mathrm{ml}$ containing about $5 \times 10^{6}$ colony-forming units (cfu). Cultures were grown in 50-ml amounts in 20-oz (568-ml) flat glass bottles which were gassed with a deoxygenated mixture of $\mathrm{CO}_{2} 10 \%$ and $\mathrm{N}_{2} 90 \%$, sealed with rubber bungs and incubated horizontally to give the maximum gas-liquid interface.

\section{Reagents}

Sodium ribonucleate from yeast was supplied by BDH Chemicals Ltd, Poole, Dorset; RNA-core Type II-C from torula yeast and RNA-core Type XI-C from bakers' yeast by Sigma 
London Chemical Company Ltd, Poole, Dorset; and bovine serum albumin (BSA) fraction V by Miles Laboratories, Stoke Poges, Bucks.

\section{Estimation of growth}

Optical densities of broth cultures were read at $450 \mathrm{~nm}$ on a Unicam SP 500 Series 2 spectrophotometer with a lightpath of $1 \mathrm{~cm}$. Colony-forming units were estimated as previously described (Lemcke et al., 1979). Samples were taken from two cultures on each occasion.

\section{Preparations tested for haemolytic activity}

Filtrates from broth cultures. Cultures were centrifuged at $15000 \mathrm{~g}$ for $30 \mathrm{~min}$ and the supernates filtered through membrane filters (Millipore, UK, Ltd, Abbey Road, London NW10 7SP) of average pore diameter (apd) $450 \mathrm{~nm}$.

Extracts from solid or semi-solid cultures. Each blood-agar plate was covered with $5 \mathrm{ml}$ of

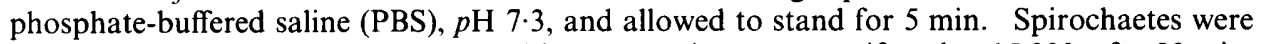
washed off with the buffer and the resulting suspension was centrifuged at $15000 \mathrm{~g}$ for $30 \mathrm{~min}$. Cultures in semi-solid blood agar were frozen at $-20^{\circ} \mathrm{C}$, thawed, and centrifuged at $15000 \mathrm{~g}$ for $30 \mathrm{~min}$. In both cases the supernates were titrated for haemolytic activity.

Suspensions of washed spirochaetes. Spirochaetes centrifuged from broth cultures or harvested from blood-agar plates were washed twice in PBS, PBS containing cysteine hydrochloride $0.05 \%$ (PBS-cysteine), or PBS-cysteine containing BSA fraction V $1 \%$. The organisms were finally resuspended in one or other of these buffers to the opacity of Standard Opacity Tube No. 4 (Burroughs Wellcome Ltd). Similar suspensions were exposed for $20 \mathrm{~s}$ to a Soniprobe (Dawe Instruments Ltd, Concord Road, London W3 0SD) with an output of $4 \mathrm{~A}$. Twofold dilutions of suspensions were titrated against sheep erythrocytes.

Supernates or filtrates from suspensions of resting spirochaetes. Initially, spirochaetes were centrifuged from $50 \mathrm{ml}$ of a 72- or 96-h culture of $T$. hyodysenteriae in RSB and resuspended without washing in $2 \mathrm{ml}$ of incubation mixture, thus giving a 25 -fold concentration of organisms. Subsequently, when different incubation mixtures were being compared, spirochaetes were washed twice in PBS and the concentration of each suspension was adjusted so that a 1 in 10 dilution had an optical density of $0 \cdot 6 \pm 0.05$ at a wavelength of $500 \mathrm{~nm}$.

The incubation mixture, based on that used for streptolysin S (Ginsburg, Bentwich and Harris, 1965), comprised PBS containing 0.001 M magnesium sulphate, $0.001 \mathrm{~m}$ glucose, $0 \cdot 1 \%$ cysteine hydrochloride, and a carrier. Originally the carrier was sodium ribonucleate at $0 \cdot 1,0 \cdot 5$ or $1.0 \%$, but in experiments to determine optimal conditions for haemolysin production this was replaced by RNA-core type II-C $(0.01,0.05$ or $0.1 \%)$, RNA-core type XI-C $(0.01,0.05$ or $0.1 \%)$, BSA fraction V $(0 \cdot 1,0.5$ or $1.0 \%)$ or Tween $80(0.4 \%)$. Suspensions in $2 \mathrm{ml}$ of incubation mixture were held at $37^{\circ} \mathrm{C}$ for $30 \mathrm{~min}$ except in experiments to determine the effects of different times and temperatures on haemolysin production. They were then chilled and centrifuged at $15000 \mathrm{~g}$ for $30 \mathrm{~min}$ at $4^{\circ} \mathrm{C}$ to remove spirochaetes. Supernates were titrated for haemolytic activity either directly or after filtration through a membrane of $450 \mathrm{~nm}$ average pore diameter.

\section{Titration of haemolysin}

Twofold dilutions of culture filtrates, supernates or filtrates from suspensions of resting spirochaetes, or suspensions of spirochaetes were made in PBS, PBS-cysteine, or PBS-cysteine containing BSA fraction $\mathrm{V} 1 \%$. To $1 \mathrm{ml}$ of each dilution was added $1 \mathrm{ml}$ of a $1 \%$ suspension in PBS-cysteine of thrice-washed sheep erythrocytes. In a few experiments pig and rabbit erythrocytes were also used. Controls consisted of buffer or fluid medium plus erythrocytes. In addition, a colour standard representing $50 \%$ haemolysis was prepared by lysing one volume of a $1 \%$ suspension of erythrocytes with three volumes of water containing cysteine hydrochloride $0.05 \%$. Tubes were incubated aerobically in a waterbath at $37^{\circ} \mathrm{C}$, except in a few experiments with washed spirochaetes when tubes were sealed under deoxygenated $10 \% \mathrm{CO}_{2}$ in $\mathrm{N}_{2}$. Tubes were read after 1,2 and $4 \mathrm{~h}$, and finally after standing at $4{ }^{\circ} \mathrm{C}$ overnight. The highest dilution showing $50 \%$ haemolysis was taken as the endpoint of each titration. 


\section{RESULTS}

\section{Haemolysin in filtrates from broth cultures}

Haemolytic activity at a titre of 128-256 was present in filtrates from 72-96-h cultures of $T$. hyodysenteriae strains $\mathrm{P} 18 \mathrm{~A}$ and $\mathrm{S} 73 / 2$ grown in RSB supplemented with $\mathrm{Na}-\mathrm{RNA} 1 \%$. Filtrates were equally active against rabbit, sheep and pig erythrocytes. Activity was not detected at the lowest dilution ( 1 in 2 ) in filtrates from $72-96-\mathrm{h}$ cultures in unsupplemented RSB or in RSB supplemented with a reduced amount $(0.5 \%)$ of Na-RNA.

Filtrates containing haemolysin were active at the same titre whether they were titrated in PBS-cysteine or in PBS-cysteine containing BSA fraction V. After storage for 12 months at $-20^{\circ} \mathrm{C}$ the titres of haemolysin had fallen only twofold. At $60^{\circ} \mathrm{C}$, however, haemolytic activity was abolished within $30 \mathrm{~min}$.

TABLE I

Haemolysin production by Treponema hyodysenteriae strain PI8A grown in rabbit-serum broth containing sodium ribonucleate $1.0 \%$

\begin{tabular}{|c|c|c|c|}
\hline \multicolumn{3}{|c|}{ Details of $T$. hyodysenteriae culture } & \multirow[b]{2}{*}{$\begin{array}{l}\text { Haemolytic titre* } \\
\text { of culture filtrate }\end{array}$} \\
\hline $\begin{array}{c}\text { Age } \\
\text { (hours) }\end{array}$ & $\begin{array}{c}\text { Optical } \\
\text { density* } \\
\text { (at } 450 \mathrm{~nm})\end{array}$ & $\begin{array}{l}\text { Viable count } \\
\quad(\mathrm{cfu} / \mathrm{ml})\end{array}$ & \\
\hline 0 & 0 & $4.4 \times 10^{4}$ & NT \\
\hline 48 & 0.04 & $3.8 \times 10^{6}$ & 32 \\
\hline 72 & 0.43 & $1.1 \times 10^{8}$ & 128 \\
\hline 96 & 1.35 & $8.8 \times 10^{7}$ & 64 \\
\hline 120 & 1.73 & $1.6 \times 10^{7}$ & $<2$ \\
\hline 144 & 1.63 & $2.5 \times 10^{6}$ & $<2$ \\
\hline 216 & 1.08 & $1.4 \times 10^{5}$ & $<2$ \\
\hline
\end{tabular}

Results represent means from two samples.

NT $=$ not tested.

* Titrated against sheep erythrocytes.

The results of determining haemolytic activity in culture filtrates of strain P18A after different periods of incubation in RSB containing Na-RNA $1 \%$ are shown in table I. The highest titres of haemolysin were recorded after incubation for $72 \mathrm{~h}$ at $37^{\circ} \mathrm{C}$. This peak coincided with the highest viable count, but occurred before the maximum optical density of the culture was reached.

\section{Haemolysin in extracts from solid or semi-solid cultures}

Haemolytic activity was not detected in the spirochaete-free washings from 72-h blood-agar cultures of $T$. hyodysenteriae strain P18A. In fluid from semi-solid cultures of the same strain haemolytic activity was found, but only at a titre of 4 . The same results were obtained whether the extracts were titrated in PBS-cysteine or in PBS-cysteine containing BSA fraction V. 


\section{Haemolytic activity of suspensions of washed spirochaetes}

Standardised suspensions of washed spirochaetes (strain P18A) from 72-h cultures in RSB or on blood agar were titrated against sheep erythrocytes. They produced haemolysis at dilutions up to 1024, provided that BSA fraction V was present in the diluent. Tests made in aerobic and anaerobic conditions gave identical results. Haemolysis was not detected if suspensions were titrated in PBS or PBS-cysteine. This contrasts with the behaviour of haemolysin in culture filtrates; such haemolysin was active when titrated in the absence of BSA fraction V.

Ultrasonically treated suspensions of strain P18A showed no haemolytic activity at 1 in 2, the lowest dilution tested, whether titrated in PBS-cysteine or PBS-cysteine containing BSA fraction $\mathrm{V}$.

\section{Haemolysin from resting spirochaetes}

When unwashed cells of strain P18A, at a concentration 25 times that of the original RSB culture, were incubated in the incubation mixture containing Na-RNA $0 \cdot 1 \%$, low titres of haemolysin $(8-16)$ were detected in the supernate. Titres of haemolysin rose to 64 and 128 when the concentration of Na-RNA was increased to 0.5 or $1.0 \%$. They were not affected by filtration through a $450-\mathrm{nm}$ membrane filter. When RNA-core type II-C was substituted for Na-RNA at $0 \cdot 01,0 \cdot 05$ or $0 \cdot 1 \%$, titres of haemolysin in the supernates were 512, 2048 and 2048, respectively. RNA-core type XI-C at the same concentrations produced titres of 256, 1024 and 2048, respectively. BSA fraction $\mathrm{V}$ at $0 \cdot 1,0.5$ or $1 \cdot 0 \%$ when used as a carrier in place of RNA gave titres of 4,32 and 8 , respectively. Tween 80 at $0.4 \%$ produced a titre of only 4 . The titres in supernates from suspensions incubated without RNA, BSA fraction V, or Tween 80 were less than 2 , showing that the presence of a carrier molecule was essential for haemolytic activity.

\section{TABLE II}

Effect on haemolysin production by resting cells of T. hyodysenteriae strain P18A* of varying the constitution of the incubation mixture

\begin{tabular}{|c|c|c|c|}
\hline \multirow[b]{2}{*}{ Incubation mixture } & \multicolumn{3}{|c|}{$\begin{array}{l}\text { Haemolytic titre in supernates from } \\
\text { incubation mixture containing }\end{array}$} \\
\hline & $\begin{array}{l}\text { Na-RNA } \\
(1 \%)\end{array}$ & $\begin{array}{l}\text { RNA-core type IIC } \\
(0.05 \%)\end{array}$ & $\begin{array}{c}\text { no } \\
\text { supplement }\end{array}$ \\
\hline Complete mixture $†(\mathrm{CM})$ & 128 & 2048 & $<2$ \\
\hline $\mathrm{CM}$ without glucose & 128 & 512 & NT \\
\hline $\mathrm{CM}$ without $\mathrm{Mg}^{2+}$ & 128 & 1024 & NT \\
\hline $\mathrm{CM}$ without cysteine- $\mathrm{HCl}$ & 128 & 1024 & NT \\
\hline PBS only & 128 & 512 & $<2$ \\
\hline PBS + glucose $(0.001 \mathrm{M})$ & NT & 1024 & NT \\
\hline $\mathrm{PBS}+\mathrm{Mg}^{2+}(0.001 \mathrm{M})$ & NT & 512 & NT \\
\hline PBS + cysteine- $\mathrm{HCl}(0 \cdot 1 \%)$ & NT & 512 & NT \\
\hline
\end{tabular}

NT $=$ not tested.

* Spirochaetes from 72-h cultures in rabbit-serum broth washed twice and resuspended to a standard opacity.

$\dagger$ Phosphate-buffered saline (PBS), $p \mathrm{H} 7 \cdot 3$, containing glucose $(0.001 \mathrm{M}), \mathrm{Mg}^{2+}(0.001 \mathrm{M})$, and cysteine hydrochloride $(0 \cdot 1 \%)$. 
The results of omitting various constituents from the incubation mixture are shown in table II. Two series of experiments were done, one with Na-RNA as the carrier, the other with RNA-core type II-C. The omission of glucose, $\mathrm{Mg}^{2+}$ and cysteine hydrochloride, or any one of these individually made no difference to the haemolytic titre of the supernates when the carrier was Na-RNA 1\%. With RNA-core as carrier, however, the omission of all three constituents resulted in a fourfold reduction in titre. The omission of glucose alone also reduced the titre fourfold, but the exclusion of $\mathrm{Mg}^{2+}$ or cysteine hydrochloride resulted in only a twofold reduction. The addition of $\mathrm{Mg}^{2+}$ or cysteine hydrochloride to an incubation mixture consisting of PBS and RNA-core type II-C $0.05 \%$ did not increase the titre of haemolysin, but the addition of glucose resulted in a twofold increase (table II). Thus, although none of the constituents except the carrier was essential for the production of haemolysin, maximum titres were obtained only with the complete incubation mixture. Of the other constituents, glucose was the most active.

Varying the concentration of glucose or substituting maltose for glucose had no effect on the amount of haemolysin produced in incubation mixtures containing Na-RNA $1 \%$ as carrier. A haemolytic titre of 128 was recorded in incubation mixtures containing glucose or maltose at $0 \cdot 1,0 \cdot 01$, or $0 \cdot 001 \mathrm{M}$.

A series of suspensions of $T$. hyodysenteriae strain $\mathrm{P} 18 \mathrm{~A}$ in the complete incubation mixture containing RNA-core type II-C $0.05 \%$ gave haemolysin titres that increased with the concentration of spirochaetes up to a certain maximum. Thus, suspensions which at a dilution of 1 in 10 had optical densities of $0 \cdot 2,0 \cdot 4,0 \cdot 6,0.8$ and 1.0 at $500 \mathrm{~nm}$, gave haemolysin titres of 256, 512, 1024, 2048 and 2048, respectively.

The effect of incubating resting cells of strain P18A at different temperatures for 30 and $60 \mathrm{~min}$ is shown in table III. Irrespective of the RNA carrier used, haemolysin production was greatly reduced at $18^{\circ} \mathrm{C}$ and $10^{\circ} \mathrm{C}$. There was also some indication

TABLE III

Haemolysin production by resting cells of T. hyodysenteriae strain P18A* incubated at different temperatures for 30 or $60 \mathrm{~min}$

\begin{tabular}{|c|c|c|c|}
\hline \multicolumn{2}{|c|}{ Incubation } & \multicolumn{2}{|c|}{$\begin{array}{l}\text { Haemolytic titre in supernates } \\
\text { from incubation mixture }{ }^{\prime} \text { containing }\end{array}$} \\
\hline $\begin{array}{l}\text { temperature } \\
\left({ }^{\circ} \mathrm{C}\right)\end{array}$ & $\begin{array}{l}\text { time } \\
(\mathrm{min})\end{array}$ & $\begin{array}{c}\text { Na-RNA } \\
(1.0 \%)\end{array}$ & $\begin{array}{c}\text { RNA-core type II-C } \\
(0.05 \%)\end{array}$ \\
\hline \multirow[t]{2}{*}{42} & 30 & 32 & 4096 \\
\hline & 60 & 16 & 2048 \\
\hline \multirow[t]{2}{*}{37} & 30 & 128 & 4096 \\
\hline & 60 & 64 & 4096 \\
\hline \multirow[t]{2}{*}{30} & 30 & 128 & 2048 \\
\hline & 60 & 128 & 2048 \\
\hline \multirow[t]{2}{*}{25} & 30 & 128 & 512 \\
\hline & 60 & 64 & 1024 \\
\hline \multirow[t]{2}{*}{18} & 30 & $<2$ & 128 \\
\hline & 60 & 2 & 128 \\
\hline \multirow[t]{2}{*}{10} & 30 & $<2$ & 64 \\
\hline & 60 & $<2$ & 64 \\
\hline
\end{tabular}

* $†$ Footnotes as in table II. 
that the low-titre haemolysin produced in the presence of Na-RNA was inactivated when incubation was extended to $60 \mathrm{~min}$ at the two highest temperatures $\left(42^{\circ} \mathrm{C}\right.$ and $37^{\circ} \mathrm{C}$ ). In experiments in which the incubation period at $37^{\circ} \mathrm{C}$ was extended beyond 30 min, the titre of haemolysin produced in the presence of Na-RNA $1 \%$ fell from 128 after $30 \mathrm{~min}$ to 64 after $60 \mathrm{~min}$, to $8-16$ after $2 \mathrm{~h}$, and to $<2$ after $4 \mathrm{~h}$. Titres of haemolysin also fell at least twofold when these supernates were stored at $4^{\circ} \mathrm{C}$ overnight and re-tested.

Like the haemolysin present in culture filtrates, haemolysin in supernates from suspensions of resting cells did not require the presence of BSA fraction $\mathrm{V}$ in the diluent used. A supernate from resting cells of strain P18A incubated with Na-RNA $1 \%$ had the same titre of haemolysin regardless of whether it was titrated in PBS-cysteine or in PBS-cysteine containing BSA fraction V $1 \cdot 0,0 \cdot 5$ or $0 \cdot 1 \%$. The titre in PBS alone was halved.

\section{Haemolysin produced by resting cells of weakly haemolytic spirochaetes}

In preliminary experiments, the haemolysins produced by resting cells from 72-96-h cultures of the weakly haemolytic spirochaetes PWS/B, 4/71, PWS/A, and M1 were compared with those produced by cells from cultures of $T$. hyodysenteriae strains P18A, S73/2 and B78 of the same age. In the presence of RNA-core type II-C $0.05 \%$, the three strains of $T$. hyodysenteriae gave haemolysin titres of 1024-2048, whereas those given by the four weakly haemolytic spirochaetes were all $<2$. When spirochaetes from a 48-h culture of strain PWS/B were used, however, haemolytic activity at a titre of 256 was detected.

Subsequently, the production of haemolysin by spirochaetes harvested from cultures of PWS/B after different periods of incubation was examined in parallel with the optical density of the cultures and their viable counts (table IV). The highest titre

TABLE IV

Haemolysin production by resting cells of porcine-intestinal spirochaete strain PWS/B harvested from cultures of different ages

\begin{tabular}{ccc|c}
\hline Details of rabbit-serum broth cultures & \\
\hline $\begin{array}{c}\text { Age } \\
\text { (hours) }\end{array}$ & $\begin{array}{c}\text { Optical } \\
\text { density } \\
\text { (at } 450 \mathrm{~nm})\end{array}$ & $\begin{array}{c}\text { Viable count } \\
(\mathrm{cfu} / \mathrm{ml})\end{array}$ & $\begin{array}{c}\text { Haemolytic titre } \\
\text { in supernate* }\end{array}$ \\
\hline 0 & 0 & $4.0 \times 10^{5}$ & $\mathrm{NT}$ \\
24 & 0.02 & $1.5 \times 10^{7}$ & $32 \dagger$ \\
30 & 0.07 & $4.5 \times 10^{7}$ & $256 \dagger$ \\
46 & 0.30 & $9.0 \times 10^{7}$ & $64 \dagger$ \\
70 & 0.68 & $6.0 \times 10^{7}$ & $<2$ \\
94 & 0.50 & $2.5 \times 10^{7}$ & $<2$ \\
\hline
\end{tabular}

$\mathrm{NT}=$ not tested.

* Supernates from suspensions of spirochaetes adjusted to a standard opacity and incubated in PBS containing glucose $(0.001 \mathrm{M}), \mathrm{Mg}^{2+}(0.001 \mathrm{M})$, cysteine hydrochloride $(0 \cdot 1 \%)$ and RNA-core type II-C $(0.05 \%)$.

$\dagger$ Prozone; less haemolysis at 1 in 2 and 1 in 4 than at higher dilutions. 
of haemolysin, 256 , was obtained from cells harvested after $30 \mathrm{~h}$ of incubation at $37^{\circ} \mathrm{C}$, when the culture was still in the logarithmic phase. By $46 \mathrm{~h}$, titres given by the cells had fallen fourfold and by $70 \mathrm{~h}$ no haemolysin was produced, even though the maximum viable count was recorded after $46 \mathrm{~h}$ and the maximum optical density after $70 \mathrm{~h}$. In titrating the haemolysin of strain PWS/B, a prozone of incomplete lysis was observed at the lowest dilutions, 1 in 2 and 1 in 4 , followed by complete lysis in the next dilutions. Washing the spirochaetes twice before incubation, in order to remove any traces of medium that might have inhibited haemolysis, failed to eliminate the prozone.

\section{Discussion}

Our results showed that RNA was required for the production of haemolysin in culture supernates or filtrates when $T$. hyodysenteriae was grown in rabbit-serum broth. Picard et al. (1979) and Knoop (1981) found some haemolytic activity in filtrates of cultures grown without RNA, but their medium was supplemented with fetal-calf serum. Rabbit serum was clearly unsatisfactory as a carrier for the treponemal haemolysin. It is noteworthy that it is also a less efficient carrier for SLS than is serum from other species (Ginsburg, 1970).

In regard to determining the time of optimal production of haemolysin in broth cultures, it is difficult to compare our results with those of Picard et al. (1979) and Knoop (1981) because of differences in the conditions of culture which undoubtedly influenced the growth rate of the spirochaetes. Knoop (1981) found that, in the absence of RNA, haemolytic titres were maximal after incubation for $2-4 \mathrm{~h}$; when RNA-core was present, however, he used an incubation period of $8 \mathrm{~h}$. It appears from our results and those of Picard et al. (1979) that haemolysin production is maximal during the late logarithmic phase and that haemolytic activity in culture supernates subsequently declines quite rapidly.

The requirement of the treponemal haemolysin for some form of carrier molecule was also borne out by the failure to extract haemolysin in any quantity from blood-agar cultures with PBS, or from semi-solid cultures by freezing and thawing. The requirement for BSA fraction $\mathrm{V}$ when suspensions of spirochaetes were titrated directly against sheep erythrocytes also suggests the necessity for a carrier.

Like SLS, the haemolysin of $T$. hyodysenteriae was released from resting cells in the absence of erythrocytes, provided that a carrier substance was present. Of the carriers tested, RNA-core was the most effective. Tween 80 and BSA fraction V, which function as carrier molecules for SLS, were much less active than RNA-core for the treponemal haemolysin. Although maximum titres were obtained from resting cells only when glucose, $\mathrm{Mg}^{2+}$ and cysteine hydrochloride were also present, omission of one or more of these constituents did not reduce haemolysin production to the extent reported for RNA-induced SLS (Ginsburg, 1970).

The treponemal haemolysin, like SLS, appeared to be oxygen stable. Anaerobic conditions were not necessary for its production from washed spirochaetes, or for the titration of haemolysin pre-formed in filtrates from cultures or resting cells. Saheb et al. (1980) also concluded that the haemolysin was oxygen resistant, because activity was retained after bubbling air through a solution of haemolysin for $2 \mathrm{~h}$. 
Our experiments and those of Saheb et al. (1980) and Knoop (1981) all suggest that the treponemal haemolysin is heat labile. It was inactivated slowly at $37^{\circ} \mathrm{C}$ and $42^{\circ} \mathrm{C}$, and rapidly at $60^{\circ} \mathrm{C}$. Even storage at $4^{\circ} \mathrm{C}$ overnight resulted in some reduction in titre. Knoop (1981) found that the haemolysin was much more stable and survived storage better if it was lyophilised. Streptolysin S, whether bound to RNA, serum or detergent is also very unstable in aqueous solution (Ginsburg, 1970).

In a classic study on SLS, Bernheimer (1949) showed that haemolysin was not produced by resting streptococci below $15^{\circ} \mathrm{C}$ or above $40^{\circ} \mathrm{C}$. Haemolysin production by resting cells of $T$. hyodysenteriae, at least in the presence of RNA-core, occurred over a wider range of temperatures. Because T. hyodysenteriae grows and produces haemolysis of blood-agar plates at $42^{\circ} \mathrm{C}$, it is not surprising that haemolysin was formed by resting spirochaetes at this temperature. Although haemolysin was detected at $10^{\circ} \mathrm{C}$ and $18^{\circ} \mathrm{C}$, titres were appreciably lower than at $30^{\circ} \mathrm{C}$ and above.

Haemolysin was also produced, albeit in small amounts, by resting cells of a weakly haemolytic intestinal spirochaete. However, haemolysin production by this strain was apparently restricted to a limited period in the growth cycle. This may merely reflect differences in the amount of haemolysin produced by this spirochaete and $T$. hydrodysententeriae. Because haemolysin is slowly inactivated at $37^{\circ} \mathrm{C}$, the smaller amounts produced by the weakly haemolytic strain would disappear more rapidly. On the other hand, the haemolysin produced by the weakly haemolytic strain showed a prozone phenomenon never observed with the haemolysin of $T$. hyodysenteriae, and this may indicate that it acts differently on erythrocytes. One explanation of the prozone is that at high concentrations the haemolysin of PWS/B has a greater affinity for RNA-core than for erythrocyte membranes.

So far, haemolysin production is the only attribute of $T$. hyodysenteriae that can be identified as a potential virulence factor. Streptolysin S, which the treponemal haemolysin resembles in several respects, is cytotoxic for leucocytes including lymphocytes, and also for platelets, cell cultures, and erythrocytes (see Jeljaszewicz, Szmigielski and Hryniewicz, 1978). Moreover, it inhibits rosette formation by $\mathrm{T}$ lymphocytes (Hryniewicz and Pryjma, 1977, 1980). It will therefore be important to determine whether the pure haemolysin of $T$. hyodysenteriae exhibits similar properties, and whether it is immunogenic. So far, partial purification of the haemolysin from culture filtrates has been reported by Saheb et al. (1980) and Knoop (1981). Our demonstration that high titres of haemolysin can be produced from resting cells suspended in a buffer much less complex than the growth medium should considerably facilitate purification for future studies.

We are indebted to Drs D. L. Harris, D. J. Taylor, and R. J. Lysons who provided strains of spirochaetes and information about them.

\section{REFERENCES}

Bernheimer, A. W. 1949. Formation of a bacterial toxin (streptolysin S) by resting cells. $J$. exp. Med., 90, 373.

BURRows, M. R. AND LEMCKE, R.M. 1981. Identification of Treponema hyodysenteriae by a rapid slide agglutination test. Vet. Rec., 108, 187.

Ginsburg, I. 1970. Streptolysin S. In Microbial toxins, vol. III, edited by T. C. Montie, S. Kadis and S. J. Ajl, Academic Press, New York, p. 99. 
GinsBurg, I., Bentwich, Z. AND HaRris, T. N. 1965. Oxygen-stable hemolysins of group A streptococci. III. The relationship of the cell-bound hemolysin to streptolysin S. J. exp. Med., 121, 633.

Harris, D. L., Glock, R. D., Christensen, C. R. and Kinyon, J. M. 1972a. Swine dysentery. I. Inoculation of pigs with Treponema hyodysenteriae (new species) and reproduction of the disease. Vet. Med., small Anim. Clin., 67, 61.

Harris, D. L., Kinyon, J. M., Mullin, M. T. and Glock, R. D. 1972b. Isolation and propagation of spirochetes from the colon of swine dysentery affected pigs. Can. J. comp. Med., 36, 74.

Hryniewicz, W. ANd Pryjma, J. 1977. Effect of streptolysin S on human and mouse T and B lymphocytes. Infect. Immun., 16, 730.

Hryniewicz, W. and Pryjma, J. 1980. The effect of streptolysin $\mathrm{S}$ on lymphocytes. In Streptococcal disease and the immune response, edited by S. E. Read and J. B. Zabriskie, Academic Press, New York, p. 199.

Hudson, M. J., Alexander, T. J. L. ANd Lysons, R. J. 1976. Diagnosis of swine dysentery: spirochaetes which may be confused with Treponema hyodysenteriae. Vet. Rec., 99, 498.

JelJaSZewiCZ, J., SZMigielski, S. AND HryniewiCZ, W. 1978. Biological effects of staphylococcal and streptococcal toxins. In Bacterial toxins and cell membranes, edited by $\mathbf{J}$. Jeljaszewicz and T. Wadström, Academic Press, London, p. 185.

KNOOP, F. C. 1981. Investigation of a hemolysin produced by enteropathogenic Treponema hyodysenteriae. Infect. Immun., 31, 193.

Lemcke, R. M., Bew, J., Burrows, M. R. And Lysons, R.J. 1979. The growth of Treponema hyodysenteriae and other porcine intestinal spirochaetes in a liquid medium. Res. vet. Sci., 26, 315 .

Lemcke, R. M. and Burrows, M.R. 1979. A disc growth-inhibition test for differentiating Treponema hyodysenteriae from other intestinal spirochaetes. Vet. Rec., 104, 548.

LemCKe, R. M. AND Burrows, M. R. 1981. A comparative study of spirochaetes from the porcine alimentary tract. J. Hyg., Camb., 86, 173.

Picard, B., Massicotte, L. And Saheb, S. A. 1979. Effect of sodium ribonucleate on the growth and the hemolytic activity of Treponema hyodysenteria. Experientia, 35, 484.

SAHEB, S. A. AND LAFLeUR, L. 1980. Characeristics of the interaction of a treponemal hemolysin with rabbit erythrocytes. Biochimie, 62, 787.

Saheb, S. A., Massicotte, L. And Picard, B. 1980. Purification and characterization of Treponema hyodysenteriae hemolysin. Biochimie, $62,779$.

TAYLOR, D. J. AND AleXANDER, T. J. L. 1971. The production of dysentery in swine by feeding cultures containing a spirochaete. Br. vet. J., 127, lviii. 